\title{
Spotlight on tocilizumab and its potential in the treatment of systemic sclerosis
}

\author{
This article was published in the following Dove Press journal: \\ Drug Design, Development and Therapy \\ 29 August 2016 \\ Number of times this article has been viewed
}

\section{Lazaros I Sakkas}

Department of Rheumatology and Clinical Immunology, Medical School, University of Thessaly, Larissa, Greece
Correspondence: Lazaros I Sakkas Department of Rheumatology and Clinical Immunology, Medical School, University of Thessaly, Biopolis, Larissa $41 \mathrm{II}$, Greece

$\mathrm{Tel}+3024 \mathrm{I} 35028 \mathrm{I} 3$

$\mathrm{Fax}+302413501016$

Email Isakkas@med.uth.gr

\begin{abstract}
Systemic sclerosis (SSc) is a multisystem disease characterized by extensive collagen deposition in skin and internal organs, fibrointimal microvasculopathy, and activation of the immune system. T cells and B cells can promote fibrosis in SSc. Interleukin (IL)-6 is implicated in the pathogenesis of SSc. IL-6 is increased in the peripheral blood and lesional skin from patients with SSc, and induces fibroblast collagen production directly and indirectly by inducing profibrotic M2 macrophages. IL- 6 also induces Th17 differentiation and promotes B cell differentiation toward Ig-producing plasma cells. IL-6 is also implicated in the pathogenesis of SSc in animal models as it is increased in mice with bleomycin-induced fibrosis, whereas neutralization of IL- 6 in these mice prevents skin fibrosis. IL- 6 acts on cells by binding to IL-6 receptor (IL-6R) which is transmembrane or soluble, and then recruits the signal-transducing glycoprotein 130 which is ubiquitously expressed. Tocilizumab is an anti-IL-6R humanized monoclonal antibody that blocks IL-6-mediated signaling. Tocilizumab has been approved for the treatment of moderate-to-severe rheumatoid arthritis, for polyarticular and systemic juvenile idiopathic arthritis, and for Castleman's disease, and is well tolerated. Case reports and a Phase II, randomized trial in SSc have shown some improvement of skin tightness and delayed deterioration of lung function. A Phase III randomized trial in SSc is anticipated.
\end{abstract}

Keywords: biologics, B cells, fibrosis, IL-6, IL-6 receptor

\section{Systemic sclerosis}

Systemic sclerosis (SSc) is a chronic disease characterized by extensive fibrosis in skin and internal organs, fibrointimal proliferation of small arteries, and activation of the immune system. The hallmark of the disease is increased extracellular matrix (ECM) deposition which is caused not only by increased ECM deposition by activated fibroblasts but also by decreased ECM degradation. Degradation of ECM components is caused by matrix metalloproteinases (MMPs), whereas tissue inhibitor of metalloproteinase 1 (TIMP-1) inhibits MMPs and thus regulates ECM turnover. In SSc, specific MMPs are inhibited by functional autoantibodies, ${ }^{1}$ whereas serum TIMP-1 levels are elevated ${ }^{2}$ and TIMP-1 expression is upregulated in SSc monocytes. ${ }^{3}$ Thus, inhibition of ECM breakdown contributes to ECM accumulation.

Although the pathogenesis of SSc is complex, both adaptive and innate immunity appear to be implicated in the accumulation of ECM in this disease. There is convincing evidence for a pathogenic role of both T cells and B cells in SSc. T cells produce profibrotic cytokines interleukin (IL)-4, IL-13, and IL-17, whereas B cells are hyperactivated and promote fibrosis through autoantibodies, profibrotic cytokines IL-6 and TGF $\beta$, and cell-cell contact with fibroblasts. ${ }^{1,4-8}$

Toll-like receptors (TLRs), receptors utilized by innate immune system, appear to be involved in SSc. TLRs recognize exogenous pathogen-associated molecular patterns 
and endogenous damage-associated molecular patterns. An endogenous ligand of TLR4, S100A8/A9 complex, is found to be increased in plasma from patients with SSc by proteomics analysis. ${ }^{9}$ TLR agonists appear to contribute to fibrosis. Hyaluronan, a component of ECM and enhanced in mouse skin with bleomycin-induced fibrosis, stimulates B cell production of IL- 6 and TGF $\beta$ primarily through TLR4. ${ }^{10}$ TLR8 stimulation by ssRNA increases the production of TIMP-1 in monocytes from SSc patients or healthy controls, and thus inhibits the breakdown of ECM. ${ }^{3}$ Nucleosome, which can stimulate TLR9, induces T cell expression of IL-4 and IL-17, and B cell Ig production. ${ }^{11}$ Serum nucleosome levels are elevated in SSc, and TLR9 is upregulated in T cells and B cells from SSc patients. ${ }^{11}$ TLR7 and TLR9 induce type I IFNregulated genes, such as Siglec in SSc monocytes, and Siglec expression is increased in tissue macrophages in SSc. ${ }^{12}$

\section{IL-6}

IL-6, a 184-aminoacid glycoprotein, is a pleiotropic cytokine produced by various cell types, predominantly macrophages and fibroblasts. IL-6 binds to IL-6 receptor (IL-6R), which is transmembrane (tIL-6R) or soluble (sIL-6R), and constitutes the $\alpha$ subunit of the receptor. IL- 6 bound to tIL-6R or sIL-6R recruits two molecules of glycoprotein 130 (gp130). gp130 constitutes the $\beta$ subunit of the complex and is the signaltransducing subunit of the receptor. IL-6R is expressed on hepatocytes, on subpopulations of leukocytes, and on megakaryocytes, whereas gp130 is ubiquitously expressed. Other IL-6 family cytokine members, such as leukemia inhibitory factor, IL-11, oncostatin M, ciliary neurotrophic factor, cardiotrophin-1, IL-27, and IL-35 bind to their specific $\alpha$ subunit of receptors and mediate their signal transduction via the common gp130 $\beta$ subunit.

IL-6 induces hepatocyte production of acute-phase proteins, such as CRP, serum amyloid A, haptoglobin, fibrinogen, and $\alpha 1$-antichymotrypsin, whereas it reduces the production of albumin and transferrin. IL- 6 also induces the production of hepcidin, which blocks the iron transporter ferroportin-1 in gut and thus reduces serum iron levels. In bone marrow, IL-6 promotes maturation of megakaryocytes and release of platelets into the circulation. ${ }^{13}$ IL-6 also plays an important role in adaptive immunity. IL-6 in combination with TGF $\beta$ induces Th17 differentiation from naïve CD4 T cells, and inhibits TGF $\beta$-induced Tregs differentiation. IL-6 also promotes $\mathrm{B}$ cell differentiation toward IgG-producing plasma cells. IL-6 signaling via the sIL-6R is called trans-signaling and mediates predominantly pro-inflammatory signals, whereas IL-6 signaling via the
tIL-6R is called classic signaling and mediates regulatory/ anti-inflammatory signals. ${ }^{13-15}$ For instance, transgenic mice overexpressing soluble gp130 which specifically blocks sIL-6R exhibit no inflammatory processes. ${ }^{16}$

IL-6 is a unique cytokine in two ways: first, it acts on cells that do not express IL-6R, and second, unlike other cytokines, its binding to sIL-6R exerts an agonist effect.

\section{IL-6 in SSc}

Serum levels of IL-6 are elevated in patients with early diffuse cutaneous SSc (dcSSc), ${ }^{17-21}$ particularly in those with lung fibrosis. ${ }^{17-19}$ Serum IL-6 levels are strongly correlated with the extent of skin fibrosis. ${ }^{18}$ Serum IL-6 levels are predictive of early functional decline and mortality in SScassociated interstitial lung disease ${ }^{22}$ and reduced long-term survival. ${ }^{20}$ IL-6 is also increased in phytohemagglutininstimulated peripheral blood mononuclear cells and in T cell lines from SSc patients. ${ }^{19}$

In SSc, skin IL-6 staining is detected in perivascular inflammatory infiltrates, endothelial cells, fibroblasts, and epidermis. ${ }^{20,21}$ High skin IL-6 expression in skin of patients with early dcSSc is associated with more severe skin involvement at 3 years, and worse long-term survival. ${ }^{20}$ Fibroblasts from affected SSc skin spontaneously produce 30 -fold more IL-6 than normal fibroblasts. ${ }^{23} \mathrm{~B}$ cells appear not only to be a source of IL-6 in SSc but also to induce IL-6 production by fibroblasts. Thus, SSc B cells stimulated with BAFF increase IL-6 production. ${ }^{24}$ It is noted that serum BAFF levels are elevated in SSc patients and correlated with the extent of skin fibrosis. ${ }^{24}$ Also, coculture of a B cell line from SSc lesional lung tissue with fibroblasts induces extraordinarily high IL-6 production by fibroblasts. ${ }^{25}$

IL-6 promotes fibrosis. In fibroblast cultures, IL-6 induces collagen production ${ }^{20,26}$ through JAK2/STAT3- and ERKdependent signaling. ${ }^{20}$ This fibroblast collagen production is also found to be through IL-6R trans-signaling, STAT3 activation, and TGF $\beta$ induction via the Gremlin protein. ${ }^{27}$ In addition, IL- 6 induces the generation of profibrotic M2 macrophages. ${ }^{28}$

\section{IL-6 in animal models of SSc}

As mentioned, IL-6 in combination with TGF $\beta$ induces differentiation of Th17 cells. Th17 cells produce profibrotic IL-17A. ${ }^{8}$ Serum levels of IL-6 are elevated in murine bleomycin-induced model of scleroderma, whereas neutralization of IL-6 improves dermal fibrosis. Thus, dermal fibrosis is reduced in IL-6 knockout mice. ${ }^{29}$ Similarly, anti-IL-6R monoclonal antibody $(\mathrm{MoAb})^{21,29}$ or active immunization 
with an IL-6 peptide ${ }^{21}$ reduces dermal thickness in bleomycininduced mouse model of SSc, and this improvement is associated with reduced T cell skin infiltrates. ${ }^{21}$ However, anti-IL-6R MoAb has no effect on fibrosis in tight-skin mice, another model of SSc. ${ }^{21}$ IL- 6 induces $\alpha$-SMA expression in IL-6 knockout mouse-derived fibroblasts in a dose-dependent manner, and this is inhibited by anti-IL-6R MoAb. ${ }^{29}$

In the murine sclerodermatous chronic graft-versus-host disease model of SSc, serum IL-6 levels are elevated, whereas administration of anti-IL-6R MoAb prevents fibrosis and this is mediated through increase in CD4+CD25+FoxP3+ Tregs. ${ }^{30}$ However, anti-IL-6R MoAb has no effect on fibrosis in established chronic graft-versus-host disease model of SSc. ${ }^{30}$

IL-6 also appears to be involved in pulmonary arterial hypertension $(\mathrm{PAH})$, a serious manifestation of SSc. Transgenic mice with lung-specific overexpression of IL-6 spontaneously develop PAH with distal arterial neointimal proliferative changes composed of endothelial cells and T cells. ${ }^{31}$ IL- 6 also appears to be involved in chronic hypoxiainduced PAH. Mice lacking IL-6 develop less severe PAH compared to wild-type mice after 2 weeks of hypoxia. ${ }^{32}$

\section{Tocilizumab}

Tocilizumab (TCZ) is an IgG1 humanized anti-IL-6R $\mathrm{MoAb}$ that binds to both sIL-6R and tIL-6R, and blocks IL-6-mediated signaling, both classic signaling and transsignaling (Figure 1). TCZ is generated by inserting the complementarity-determining regions of a mouse anti-human IL-6R antibody into IgG1 $\kappa$ at the cDNA level. ${ }^{33}$

TCZ has been proved as an effective therapy for various autoimmune inflammatory diseases. It is approved for the treatment of moderate-to-severe rheumatoid arthritis (RA), polyarticular and systemic juvenile idiopathic arthritis, and multicentric Castleman's disease, a multicentric disease of non-clonal lymphadenopathy. TCZ has been off-label used for the treatment of refractory cases of polymyalgia rheumatica/giant cell arteritis, Takayasu arteritis, and adultonset Still's disease. In RA, TCZ is used at a dose of $8 \mathrm{mg} / \mathrm{kg}$ intravenously every 4 weeks or $162 \mathrm{mg}$ subcutaneously every 2 weeks.

In patients with RA, TCZ decreases peripheral blood activated $\mathrm{B}$ cells and $\mathrm{T}$ cells $\mathrm{s}^{34}$ and the frequency of memory B cells. ${ }^{35}$ Also, in patients with RA, clinical improvement after TCZ treatment is associated with expansion of TGF $\beta+$ CD25 high B cells considered to be regulatory B cells. ${ }^{36}$

TCZ is well tolerated. Adverse effects reported include risk of infections (mostly pneumonia and cellulitis), neutropenia, thrombocytopenia, elevated liver enzymes, elevated total cholesterol, low-density lipoprotein, and triglycerides. ${ }^{37}$ TCZ restores the depression by IL-6 activity of CYP450 enzymes in RA and decreases bioavailability of drugs that are substrates of CYP450 enzymes. Thus, simvastatin levels decrease by $57 \%$ after TCZ infusion. Therefore, close monitoring is required for drugs that are metabolized by CYP450 enzymes and have a narrow therapeutic window, such as warfarin.

Serum IL-6 levels are elevated in patients with RA or Castleman's disease treated with TCZ because sIL-6R bound to TCZ hinders IL-6 clearance from the circulation. ${ }^{38}$

\section{TCZ in SSc}

SSc is a complex disease with frequent serious manifestations that reduce life expectancy. Once fibrosis causes symptoms, there is no effective therapy. Thus far, there are
A

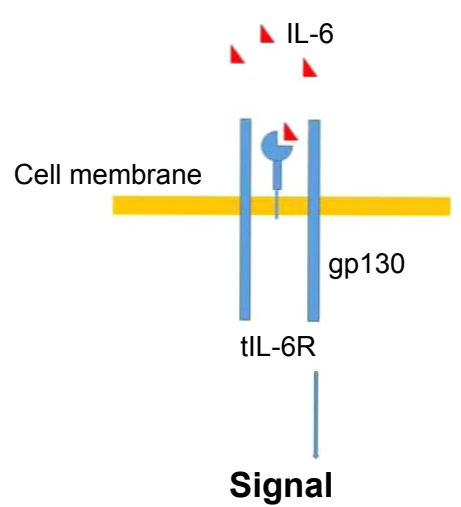

B

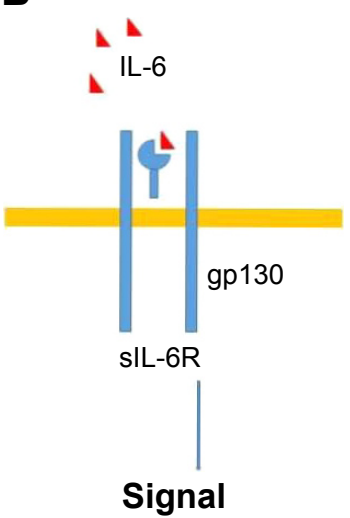

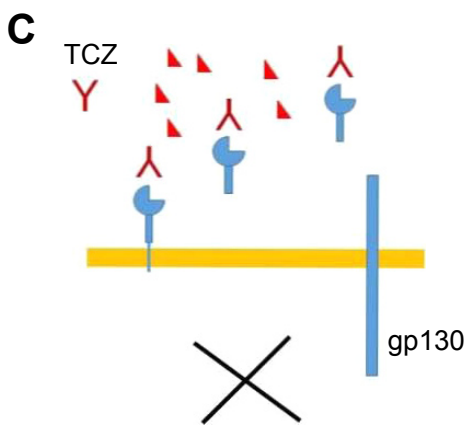

No signal

Figure I TCZ: mechanism of action

Notes: IL-6 binds to tIL-6R (A) and sIL-6R (B), and this recruits two molecules of signal-transducing gp I 30 to activate cells. (C) TCZ binds to both tIL-6R and sIL-6R and blocks the action of IL-6.

Abbreviations: TCZ, tocilizumab; IL-6, interleukin-6; tIL-6R, transmembrane IL-6 receptor; sIL-6R, soluble IL-6 receptor; gP I30, glycoprotein I30. 
few randomized trials in SSc, and today, medications used in SSc include methotrexate for skin thickness, and cyclophosphamide or mycophenolate mofetil for interstitial lung disease with limited efficacy. ${ }^{39-41} \mathrm{~B}$ cell-depleting therapy with anti-CD20 MoAb (rituximab) has also been shown to reduce skin thickness and stabilize lung function in a small series of patients. ${ }^{42}$

Blocking IL-6 signaling with TCZ offers an advantage over previous targeted treatments because IL- 6 is involved in both innate and adaptive immunity. Even B cell depletion therapy in SSc may work through IL-6, by eliminating IL-6producing B cells. For instance, mice with B cell-specific IL-6 deficiency were reported to exhibit less severe disease than mice with wild-type B cells, and B cell depletion treatment ameliorated experimental autoimmune encephalomyelitis only in mice with IL-6-producing B cells. ${ }^{43}$ Additionally, rituximab nonresponders among RA patients were shown to exhibit persistent IL-6 elevated blood levels despite synovial B cell depletion, ${ }^{44}$ and TCZ provided better efficacy than TNF inhibitors or abatacept after rituximab failure in RA patients. ${ }^{45}$

TCZ has exhibited encouraging results in case reports on SSc overlap syndromes ${ }^{46,47}$ and case reports or small observational studies on SSc. ${ }^{48-52}$ In a study, two patients with SSc, one with lung fibrosis and the other with chronic renal failure after scleroderma renal crisis, received TCZ for 6 months. There was significant reduction of skin tightness and histological thinning of skin collagen bundles in both patients, and also improvement of renal function. There was no change in lung function. ${ }^{48}$ In a small observational 5-month study in patients with SSc and refractory polyarthritis, TCZ achieved a good European League Against Rheumatism response in ten out of 15 patients with arthritis. ${ }^{49}$ In a patient with dcSSc, TCZ reduced Rodnan skin score from 35 to 7 and expanded range of motion of joints within 16 months.$^{51}$ In two out of three SSc patients with refractory disease, TCZ improved skin score and completely healed digital ulcers. ${ }^{50}$ Recently, a Phase II, double-blind, placebo-controlled randomized trial of TCZ (162 mg administered subcutaneously per week) in 87 patients with early SSc ( $<5$ years from first non-Raynaud's symptom) has been published. ${ }^{53}$ Overall, TCZ decreased the modified Rodnan skin score but not statistically significantly so. However, more patients in the TCZ group (37\%) achieved clinically important decrease in skin score ( $>4.7$ units) compared to patients in the placebo group (25\%). Fewer patients in the TCZ group than in the placebo group had worsening in the percent of forced vital capacity. At 48 weeks, $10 \%$ in the TCZ group and $23 \%$ in the placebo group had $>10 \%$ (absolute) decrease in the percent predicted forced vital capacity values. Interestingly, TCZ treatment resulted in downregulation of genes associated with M2 macrophages in skin biopsies. Serious infections were more common in the TCZ group (16\%) than in the placebo group (5\%), and one patient in the TCZ group died. A 2-year Phase III randomized controlled trial of TCZ (162 mg administered subcutaneously per week) in SSc is underway (NCT02453256).

Although TCZ has a good record in terms of adverse effects, physicians should be alert for any new adverse effects when TCZ is used therapeutically for new diseases. For instance, patients with SSc often have digital ulcers that are frequently infected. TCZ may blunt CRP increase in these patients and delay diagnosis of infection. Another watchful area may be the gut. TCZ improved skin score in two patients with SSc, but both patients experienced bowel pseudo-obstruction. ${ }^{52}$ This latter effect might be explained by the beneficial effect IL-6 may exert on gut epithelia after injury. For instance, in two murine models of gut injury, one with biopsy wound and the other with bacteria-induced colitis, inhibition of IL-6 resulted in decreased epithelial proliferation and impaired wound healing. ${ }^{54}$

\section{Future perspectives}

$\mathrm{SSc}$ is a frequently serious disease with devastating manifestations, and treatment of this disease thus far is suboptimal, to say the least. TCZ blocking the effects of IL-6, which is a profibrotic cytokine involved in both adaptive and innate immunity, raises expectations for efficacy in SSc. Early results from case series and case reports, and a Phase II study are encouraging. The publication of new classification criteria for SSc is expected to help in early diagnosis of SSc and implementing early treatment. Blocking IL-6 signaling early in the course of the disease, when inflammatory infiltrates are prominent, is expected to be more efficacious and is hoped to brighten the prognosis of this frequently devastating disease.

\section{Disclosure}

The author reports no conflicts of interest in this work.

\section{References}

1. Sakkas LI, Bogdanos DP. Systemic sclerosis: new evidence re-enforces the role of B cells. Autoimmun Rev. 2016;15(2):155-161.

2. O'Reilly S, Ciechomska M, Cant R, Hugle T, van Laar JM. Interleukin-6, its role in fibrosing conditions. Cytokine Growth Factor Rev. 2012;23(3): 99-107.

3. Ciechomska M, Huigens CA, Hugle T, et al. Toll-like receptor-mediated, enhanced production of profibrotic TIMP-1 in monocytes from patients with systemic sclerosis: role of serum factors. Ann Rheum Dis. 2013; 72(8):1382-1389. 
4. Kurasawa K, Hirose K, Sano H, et al. Increased interleukin-17 in patients with systemic sclerosis. Arthritis Rheum. 2000;43(11):2455-2463.

5. Sakkas LI, Platsoucas CD. Is systemic sclerosis an antigen-driven T cell disease. Arthritis Rheum. 2004;50(6):1721-1733.

6. Sakkas LI, Chikanza IC, Platsoucas CD. Mechanisms of disease: the role of immune cells in the pathogenesis of systemic sclerosis. Nat Clin Pract Rheumatol. 2006;2(12):679-685.

7. Radstake TR, van Bon L, Broen J, et al. The pronounced Th17 profile in systemic sclerosis $(\mathrm{SSc})$ together with intracellular expression of TGFbeta and INFgamma distinguishes SSc phenotypes. PLoS One. 2009;4(6):e5903.

8. Okamoto Y, Hasagawa M, Matsushita T, et al. Potential roles of interleukin-17A in the development of skin fibrosis in mice. Arthritis Rheum. 2012;64(11):3726-3735.

9. Van Bon L, Cossu M, Loof A, et al. Proteomic analysis of plasma identifies the toll-like receptor agonists $\mathrm{S} 100 \mathrm{~A} 8 / \mathrm{A} 9$ as a novel possible marker for systemic sclerosis phonotype. Ann Rheum Dis. 2014;73(8): $1585-1589$.

10. Yoshizaki A, Iwata Y, Komura K, et al. CD19 regulates skin and lung fibrosis via Toll-like receptor signaling in a model of bleomycin-induced scleroderma. Am J Pathol. 2008;172(6):1650-1663.

11. Yoshizaki A, Taniguchi T, Saiqusa R, et al. Nucleosome in patients with systemic sclerosis: possible association with immunological abnormalities via abnormal activation of T and B cells. Ann Rheum Dis. Epub 2015 Nov 13.

12. York MR, Nagai T, Mangini AJ, Lemaire R, van Seventer JM, Lafyatis R. A macrophage marker, Siglec-1, is increased on circulating monocytes in patients with systemic sclerosis and induced by type I interferons and toll-like receptor agonists. Arthritis Rheum. 2007;56(3) 1010-1020.

13. Tanaka T, Narazaki M, Kishimoto T. IL-6 in inflammation, immunity, and disease. Cold Spring Harb Perspect Biol. 2014;6(10):a016295.

14. Scheller J, Garbers C, Rose-John S. Interleukin-6: from basic biology to selective blockade of pro-inflammatory activities. Semin Immunol. 2014;26(1):2-12.

15. Garbers C, Aparicio-Sieqmund S, Rose-John S. The IL-6/gp130/STAT3 signaling axis: recent advances towards specific inhibition. Curr Opin Immunol. 2015;34:75-82.

16. Rabe B, Chalaris A, Man U, et al. Transgenic blockade of interleukin 6 transsignaling abrogates inflammation. Blood. 2008;111(3): 1021-1028.

17. Hasegawa M, Sato S, Fujimoto M, Ihn H, Kikuchi K, Takehara K. Serum levels of interleukin 6(IL-6), oncostatin M, soluble IL-6 receptor, and soluble gp130 in patients with systemic sclerosis. J Rheumatol. 1998;25(2):308-313.

18. Sato S, Hasegawa M, Takehara K. Serum levels of interleukin-6 and interlukin-10 correlate with total skin thickness score in patients with systemic sclerosis. J Dermatol Sci. 2001;27(2):140-146.

19. Scala E, Pallotta S, Frezzolini A, et al. Cytokine and chemokine levels in systemic sclerosis: relationship with cutaneous and internal organ involvement. Clin Exp Immunol. 2004;138(3):540-546.

20. Khan K, Xu S, Nihtyanova S, et al. Clinical and pathological significance of interleukin 6 overexpression in systemic sclerosis. Ann Rheum Dis. 2012;71(7):1235-1242.

21. Desallais L, Avouac J, Frechet M, et al. Targeting IL- 6 by both passive or active immunization strategies prevents bleomycin-induced skin fibrosis. Arthritis Res Ther. 2014;16(4):R157.

22. De Lauretis A, Sestini P, Pantelidis P, et al. Serum interleukin 6 is predictive of early functional decline and mortality in interstitial lung disease associated with systemic sclerosis. J Rheumatol. 2013;40:435-446.

23. Feghali CA, Bost KL, Boulware DW, Levy LS. Control of IL-6 expression and response in fibroblasts from patients with systemic sclerosis. Autoimmunity. 1994;17(4):309-318.

24. Matsushita T, Hasegawa M, Yanaba K, Kodera M, Takehara K, Sato $\mathrm{S}$. Elevated serum BAFF levels in patients with systemic sclerosis: enhanced BAFF signaling in systemic sclerosis B lymphocytes. Arthritis Rheum. 2006;54(1):192-201.
25. Kondo K, Okada T, Matsui T, et al. Establishment and characterization of a human $\mathrm{B}$ cell line from the lung tissue of a patient with scleroderma; extraordinary high level of IL-6 secretion by stimulated fibroblasts. Cytokine. 2001;13(4):320-326.

26. Duncan MR, Berman B. Stimulation of collagen and glycosaminoglycan production in cultured human adult dermal fibroblasts by recombinant human interleukin 6. J Invest Dermatol. 1991;97(4):686-692.

27. O'Reilly S, Ciechomska M, Cant R, van Laar JM. Interleukin-6 (IL-6) trans signaling drives a STAT3-dependent pathway that leads to hyperactive transforming growth factor- $\beta$ (TGF- $\beta$ ) signaling promoting SMAD3 activation and fibrosis via Gremlin protein. $J$ Biol Chem. 2014;289(14):9952-9960.

28. Mauer J, Denson JL, Bruning JC. Versatile functions for IL-6 in metabolism and cancer. Trends Immunol. 2015;36(2):92-101.

29. Kitaba S, Murota H, Terao M, et al. Blockade of interleukin-6 receptor alleviates disease in mouse model of scleroderma. Am J Pathol. 2012; 180(1):165-176

30. Le Huu D, Matsushita T, Jin G, et al. IL-6 blockade attenuates the development of murine sclerodermatous chronic graft-versus-host disease. J Invest Dermatol. 2012;132(12):2752-2761.

31. Steiner MK, Syrkina OL, Kolliputi N, Mark EJ, Hales CA, Waxman AB. Interleukin-6 overexpression induces pulmonary hypertension. Circ Res. 2009;104(2):236-244.

32. Savale L, Tu L, Rideau D, et al. Impact of interleukin-6 on hypoxiainduced pulmonary hypertension and lung inflammation in mice. Respir Res. 2009;10:6.

33. Sato K, Tsuchiya M, Saldanha J, et al. Reshaping a human antibody to inhibit the interleukin 6-dependent tumor cell growth. Cancer Res. 1993;53(4):851-856.

34. Shirota Y, Yarboro C, Fischer R, Pham TH, Lipsky P, Illei GG. Impact of anti-interleukin-6 receptor blockade on circulating $\mathrm{T}$ and $\mathrm{B}$ cell subsets in patients with systemic lupus erythematosus. Ann Rheum Dis. 2013; 72:118-128.

35. Roll P, Muhammad K, Schumann M, et al. In vivo effects of the antiinterleukin-6 receptor inhibitor tocilizumab on the B cell compartment. Arthritis Rheum. 2011;63:1255-1264.

36. Snir A, Kessel A, Haj T, Rosner I, Slobodin G, Toubi E. Anti-IL-6 receptor antibody (tocilizumab): a B cell targeting therapy. Clin Exp Rheumatol. 2011;29:697-700.

37. Shetty A, Hanson R, Korsten P, et al. Tocilizumab in the treatment of rheumatoid arthritis and beyond. Drug Des Devel Ther. 2014;8: 349-364.

38. Nishimoto N, Terao K, Mima T, Nakahara H, Takagi N, Kakehi T. Mechanisms and pathologic significances in increase in serum interleukin-6 (IL-6) and soluble IL-6 receptor after administration of an anti-IL-6 receptor antibody, tocilizumab, in patients with rheumatoid arthritis and Castleman disease. Blood. 2008;112(10):3959-3964.

39. Kowal-Bielecka O, Landewe R, Avouac J, et al. EULAR recommendations for the treatment of systemic sclerosis: a report from the EULAR Scleroderma Trials and Research group (EUSTAR). Ann Rheum Dis. 2009;68(5):620-628.

40. van Laar JM, Farge D, Sont JK, et al. Autologous hematopoietic stem cell transplantation vs intravenous pulse cyclophosphamide in diffuse cutaneous systemic sclerosis: a randomized clinical trial. JAMA. 2014;311(24):2490-2498.

41. Omair MA, Alahmadi A, Johnson SR. Safety and effectiveness of mycophenolate in systemic sclerosis. A systematic review. PLoS One. 2015; 10(5): 0124205.

42. Giuggioli D, Lumetti F, Colaci M, Fallahi P, Antonelli A, Ferri C. Rituximab in the treatment of patients with systemic sclerosis. Our experience and review of the literature. Autoimmun Rev. 2015;14(11): 1072-1078.

43. Barr TA, Shen P, Brown S, et al. B cell depletion therapy ameliorates autoimmune disease through ablation of IL-6-producing B cells. $J$ Exp Med. 2012;209(5):1001-1010. 
44. Das S, Vital EM, Horton S, et al. Abatacept or tocilizumab after rituximab in rheumatoid arthritis? An exploratory study suggests nonresponse to rituximab is associated with persistently high IL-6 and better clinical response to IL-6 blocking therapy. Ann Rheum Dis. 2014;73(5): 909-912.

45. Walker UA, Jaeger VK, Chatzidionysiou K, et al. Rituximab done: what's next in rheumatoid arthritis? A European observational longitudinal study assessing the effectiveness of biologics after rituximab treatment in rheumatoid arthritis. Rheumatology (Oxford). 2016;55(2): 230-236.

46. Kondo M, Murakawa Y, Matsumura T, et al. A case of overlap syndrome successfully treated with tocilizumab: a hopeful treatment strategy for refractory dermatomyositis? Rheumatology (Oxford). 2014;53(10): 1907-1908.

47. Saito E, Sato S, Nogi S, et al. A case of rheumatoid arthritis and limited systemic sclerosis overlap successfully treated with tocilizumab for arthritis and concomitant generalized lymphadenopathy and primary biliary cirrhosis. Case Rep Rheumatol. 2014;2014:386328.

48. Shima Y, Kuwahara Y, Murota H, et al. The skin of patients with systemic sclerosis softened during the treatment with anti-IL-6 receptor antibody tocilizumab. Rheumatology (Oxford). 2010;49(12):2408-2412.
49. Elhai M, Meunier M, Matucci-Cerinic M, et al. Outcomes of patients with systemic sclerosis-associated polyarthritis and myopathy treated with tocilizumab or abatacept: a EUSTAR observational study. Ann Rheum Dis. 2013;72(7):1217-1220.

50. Fernandes das Neves M, Oliveira S, Amaral MC, Delgado Alves J. Treatment of systemic sclerosis with tocilizumab. Rheumatology (Oxford). 2015;54(2):371-372.

51. Shima Y, Hosen N, Hirano T, et al. Expansion of range of joint motion following treatment of systemic sclerosis with tocilizumab. Mod Rheumatol. 2015;25(1):134-137.

52. Frech TM, Hudson M. Protective role of interleukin-6 in systemic sclerosis gastrointestinal tract involvement: case report and review of the literature. Clin Exp Rheumatol. 2015;33(4 Suppl 91):S179-S181.

53. Khanna D, Denton CP, Jahreis A, et al. Safety and efficacy of subcutaneous tocilizumab in adults with systemic sclerosis (faSScinate): a phase 2, randomised, controlled trial. Lancet. Epub 2016 May 5.

54. Kuhn KA, Manieri NA, Liu TC, Stappenbeck TS. IL-6 stimulates intestinal epithelial cell proliferation and repair after injury. PLoS One. 2014;9:e114195.
Drug Design, Development and Therapy

\section{Publish your work in this journal}

Drug Design, Development and Therapy is an international, peerreviewed open-access journal that spans the spectrum of drug design and development through to clinical applications. Clinical outcomes, patient safety, and programs for the development and effective, safe, and sustained use of medicines are the features of the journal, which

\section{Dovepress}

has also been accepted for indexing on PubMed Central. The manuscript management system is completely online and includes a very quick and fair peer-review system, which is all easy to use. Visit http://www.dovepress.com/testimonials.php to read real quotes from published authors. 